\title{
Correction to: On the distribution of links in financial networks: structural heterogeneity and functional form
}

\section{Thomas Lux ${ }^{1}$}

Published online: 8 October 2019

(c) Springer-Verlag GmbH Germany, part of Springer Nature 2019

\section{Correction to: Empirical Economics https://doi.org/10.1007/s00181-018-1569-6}

In the original publication, the article title was incorrectly published as "On the distribution of links in financial networks: structural heterogeneity and functional".

The correct article title is "On the distribution of links in financial networks: structural heterogeneity and functional form".

The original article has been updated.

Publisher's Note Springer Nature remains neutral with regard to jurisdictional claims in published maps and institutional affiliations.

The original article can be found online at https://doi.org/10.1007/s00181-018-1569-6.

$\triangle$ Thomas Lux

lux@economics.uni-kiel.de

1 Department of Economics, University of Kiel, Kiel, Germany 